\title{
Increased epicardial adipose tissue thickness is a predictor of new-onset diabetes mellitus in patients with coronary artery disease treated with high-intensity statins
}

Jeehoon Kang 1,2, Young-Chan Kim², Jin Joo Park', Sehun Kim³ , Si-Hyuck Kang ${ }^{1}$, Young Jin Cho', Yeonyee E. Yoon ${ }^{1}$, Il-Young Oh ${ }^{1}$, Chang-Hwan Yoon ${ }^{1}$, Jung-Won Suh ${ }^{1}$, Young-Seok Cho ${ }^{1,4^{*}} \mathbb{C}^{\mathbb{C}}$, Tae-Jin Youn ${ }^{1,4}$, In-Ho Chae ${ }^{1,4}$ and Dong-Ju Choi ${ }^{1,4}$

\begin{abstract}
Background: Statins are widely used for lipid lowering in patients with coronary artery disease (CAD), but increasing evidence indicates an association between statin use and new-onset of diabetes mellitus (NODM). Epicardial adipose tissue (EAT) refers to the visceral fat surrounding the heart, which is associated with metabolic diseases. We sought to determine the association between EAT thickness and NODM in CAD patients treated with high-intensity statins.

Methods: We conducted a retrospective medical record review of CAD patients treated with high-intensity statins for at least 6 months after percutaneous coronary intervention performed between January 2009 and June 2013 at Seoul National University Bundang Hospital. EAT thickness was measured by echocardiography using standardized methods.

Results: A total of 321 patients were enrolled, who received high-intensity statins for a mean of 952 days; atorvastatin $40 \mathrm{mg}$ in 204 patients (63.6\%), atorvastatin $80 \mathrm{mg}$ in 57 patients (17.8\%), and rosuvastatin $20 \mathrm{mg}$ in 60 patients (18.7\%). During the follow-up period of $3.9 \pm 1.7$ years, NODM occurred in 40 patients (12.5\%). On Cox proportionalhazard regression analysis, EAT thickness at systole [for each $1 \mathrm{~mm}$ : hazard ratio (HR) 1.580; 95\% confidence interval (CI) 1.346-1.854; $P<0.001$ ] and prediabetes at baseline (HR 4.321; 95\% Cl 1.998-9.349; $P<0.001$ ) were the only independent predictors of NODM. Using binary cutoff values derived from the receiver operating characteristic curve analysis, EAT thickness at systole larger than $5.0 \mathrm{~mm}$ had an HR of $3.402(95 \% \mathrm{Cl} 1.751-6.611, P<0.001)$, sensitivity of $52.5 \%$, and specificity of $80.8 \%$ for predicting NODM. Also, patients with EAT thickness $\geq 5 \mathrm{~mm}$ and prediabetes at baseline had a 12.0-times higher risk of developing NODM compared to the risk noted in patients with EAT thickness $<5 \mathrm{~mm}$ and normal glucose tolerance at baseline.
\end{abstract}

Conclusion: Epicardial adipose tissue thickness at systole is a consistent independent predictor of NODM in patients with CAD treated with high-intensity statins. Such predictors may help physicians plan adequate surveillance for early detection of NODM.

Keywords: Statin, New-onset diabetes mellitus, Epicardial adipose tissue, Coronary artery disease, Echocardiography

\footnotetext{
*Correspondence: flammeus1@gmail.com

1 Department of Internal Medicine, Seoul National University Bundang

Hospital, 82 Gumiro173 Beongil, Bundang, Seongnam, Gyeonggi 13620,

South Korea

Full list of author information is available at the end of the article
} 


\section{Introduction}

Epicardial adipose tissue (EAT) refers to the visceral fat surrounding the heart, which can be easily measured in the clinic with standard transthoracic echocardiography [1]. Previous studies have shown the relationship of EAT with metabolic syndrome [2], atherosclerosis [3], glucose intolerance [4] and high blood pressure [5]. Especially in patients with coronary artery disease, EAT can release free fatty acid in the proximity of coronaries arteries, which disturbs vascular homeostasis and endothelial function [6]. Based on various studies, EAT has been suggested to be a promising indicator for the detection of high cardio-metabolic risk [7].

In patients with high cardiovascular risk, statins have been widely used to lower lipid levels. Although statins are effective in reducing the rate of cardiovascular events and mortality [8], there are consistent concerns regarding the association between statin use and increased rates of diabetes mellitus (DM) $[9,10]$. Despite the clinical importance of NODM in patients with cardiovascular disease, previous studies have shown inconsistent results regarding the predictors of statin-associated NODM [11-13].

Because EAT is a sensitive biomarker of metabolic status, we hypothesized that EAT thickness may be associated with the occurrence of glucose intolerance in patients with coronary artery disease (CAD) treated with high-intensity statin therapy. We also evaluated the clinical utility of EAT thickness as a predictor of NODM in these patients.

\section{Methods}

\section{Study population}

The study retrospectively enrolled patients who underwent percutaneous coronary intervention (PCI) between January 2009 and June 2013, received high-intensity statin treatment for at least 6 months, and had at least one baseline echocardiographic evaluation within 3 months after PCI at Seoul National University Bundang Hospital. We excluded patients with DM at baseline or no clinical/laboratory information regarding DM status, patients with a follow-up duration less than 6 months, and patients with a poor echocardiographic image quality for the measurement of EAT thickness (Additional file 1: Figure S1). PCI was performed using standard techniques, and follow-up was performed according to routine clinical guidelines. For each patient, the followup duration was calculated based on the prescriptions of high-intensity statins. High-intensity statin therapy, defined as either atorvastatin (40 or $80 \mathrm{mg}$ ) or rosuvastatin $(20$ or $40 \mathrm{mg}$ ), had been administered according to the 2013 American College of Cardiology/American Heart Association guidelines [8]. DM was defined as fasting blood glucose levels $\geq 126 \mathrm{mg} / \mathrm{dL}$, glycated hemoglobin levels $\geq 6.5 \%(48 \mathrm{mmol} / \mathrm{mol})$, and $/$ or the need for oral hypoglycemic agents or insulin. If there was no clear clinical diagnosis, or if a patient had discordant results from two different tests, a second test was searched for confirmation. Prediabetes was defined as fasting blood glucose levels of $100-125 \mathrm{mg} / \mathrm{dL}$ or glycated hemoglobin levels of $5.7-6.4 \%$ (39-47 mmol/mol) [14].

The study protocol was approved by the Institutional Review Board of Seoul National University Bundang Hospital and was conducted according to the principles of the Declaration of Helsinki.

\section{Measurement of EAT thickness}

All subjects underwent echocardiographic examination performed using commercially available ultrasound machines (Vivid E9, GE Healthcare, Chicago, USA; EPIQ 7, Philips Healthcare, Amsterdam, The Netherlands), and standard examination was performed with the patient in left lateral position. Left ventricular ejection fraction was calculated with the modified biplane Simpson's method. EAT thickness was measured at the end of systole and diastole on the free wall of the right ventricle in the parasternal long-axis view on standard transthoracic echocardiography, and was defined as an echo-free or hypoechoic area adjacent to the right ventricle (Additional file 1: Figure S2). This method was validated in previous studies and shown to be strongly correlated with various metabolic markers [1,7]. Only the maximum EAT thickness values were measured. The measurement was performed for two beats, and the average value was retained.

\section{Statistical analysis}

Data are presented as numbers and frequencies for categorical variables and as median and interquartile ranges for continuous variables, and were compared using Student's t-test or the Mann-Whitney U test. To compare the groups, the $x^{2}$ test (or the Fisher's exact test when any expected cell count was $<5$ for a 2-by-2 table) was used for categorical variables, and the unpaired Student t-test or one-way analysis of variance was applied for continuous variables.

In the multivariate analysis performed to identify variables influencing NODM, we used the multivariable Cox proportional hazard model. Candidate variables with $P<0.10$ in the univariate analyses, duration of statin treatment, and previously described risk factors of DM [i.e., age, male sex, body mass index (BMI), and hypertension] were included in the model $[15,16]$. For the sensitivity analysis of predictors of progression of glucose intolerance, we used the binary logistic model based on multiple variables. Variables included in the logistic 
regression model were identical to those of the multivariable Cox proportional hazard model. To determine the best cutoff value of EAT thickness that would be included in the predictive model, we performed receiver operating characteristic curve analysis. To determine intraobserver variability, one of the authors (JK) measured EAT thickness at systole and diastole twice at an interval of $>30$ days. Agreement was analyzed by means of the Bland-Altman plot (Additional file 1: Figure S3) and by determination of the intraclass correlation coefficient using the two-way mixed model (coefficient for EAT thickness at systole: 0.936 [0.916-0.951]; coefficient for EAT thickness at diastole: 0.943 [0.925-0.956]).

All statistical tests were two-tailed. A two-sided probability value less than 0.05 was considered to indicate statistical significance. Statistical tests were performed using SPSS version 20 (SPSS Inc., Chicago, IL, USA).

\section{Results}

\section{Baseline characteristics and EAT thickness}

A total of 321 patients were enrolled in this study, according to the flow chart provided in Additional file 1: Figure S1. The mean age was 59.9 years, $74 \%$ of patients were male patients, and $64 \%$ presented with acute coronary syndrome. The patients received high-intensity statins for a median of 930 days; atorvastatin $40 \mathrm{mg}$ in 204 patients (63.6\%), atorvastatin $80 \mathrm{mg}$ in 57 patients (17.8\%), and rosuvastatin $20 \mathrm{mg}$ in 60 patients $(18.7 \%$; Table 1).

New-onset diabetes mellitus occurred in 40 patients (12.5\%), with the incidence of NODM increasing gradually over the course of a mean follow-up of 3.9 years. Regarding baseline characteristics, patients with NODM had a higher frequency of baseline prediabetes, and higher levels of fasting blood glucose and HbA1c. Furthermore, among echocardiographic variables, EAT thickness at diastole and systole were significantly larger in the NODM group than in the non-NODM group (Additional file 1: Figure S4), whereas other variables did not show significant difference between the two groups. Regarding the relationship between variables, we found a moderate positive correlation of EAT thickness with HbA1c (Pearson correlation coefficient 0.307, P $<0.001$, Additional file 1: Figure S5).

\section{Predictors of NODM}

Regarding factors associated with NODM, univariate Cox regression analysis showed that EAT thickness and prediabetes at baseline were significant predictors of NODM (Table 2), which remained significant after multivariate adjustment for significant covariates (for each $1 \mathrm{~mm}$ of EAT thickness at systole: hazard ratio (HR) of 1.580 , 95\% confidential interval (CI) of 1.346-1.854,
$P<0.001$; for prediabetes at baseline: HR 4.321, 95\% CI 1.998-9.349, $P<0.001$; Table 2). Using binary cutoff values derived from the receiver operating characteristic curve analysis, EAT thickness at systole equal to or larger than $5.0 \mathrm{~mm}$ showed a sensitivity of $52.5 \%$, and specificity of $80.8 \%$ for predicting NODM (Fig. 1). Moreover, the HR for NODM in patients with EAT thickness $\geq 5 \mathrm{~mm}$ was 3.402 (95\% CI 1.751-6.611, $P<0.001$ ), showing that EAT thickness remained as an independent predictor of NODM after adjusting clinical variables, including prediabetes at baseline.

\section{Risk factors of NODM}

When we stratified the patients into four groups according to EAT thickness at systole and presence of prediabetes, the incidence of NODM was highest in patients with EAT thickness $\geq 5 \mathrm{~mm}$ and prediabetes at baseline (17 out of 40 patients; $42.5 \%$ ), which was 12.0 -fold higher than that in patients with EAT thickness $<5 \mathrm{~mm}$ and without prediabetes at baseline (5 out of 153 patients; 3.3\%, Fig. 2a). On Kaplan-Meier curve analysis and Cox regression analysis, patients with both risk factors had a significantly higher risk for NODM (Fig. 2b, Table 3). Meanwhile, patients with either one of the risk factors (i.e., those with EAT thickness $\geq 5 \mathrm{~mm}$ without prediabetes and those with EAT thickness $<5 \mathrm{~mm}$ with prediabetes) had a similar risk for NODM $(P=0.509)$.

\section{Sensitivity analysis for progression of glucose intolerance}

To evaluate the association between EAT thickness and gradual impairment in glucose tolerance, we stratified the patients into two groups according to the progression of glucose intolerance (progression vs. no progression; Additional file 2: Table S1). Progression of glucose intolerance was noted in about $40 \%$ of the total study population (progression group), among whom 81 patients $(25.2 \%)$ showed normal glucose tolerance at baseline and developed new-onset prediabetes during the follow-up period. The progression group had more prediabetic patients, higher levels of fasting blood glucose, and marginally longer statin treatment duration. Additionally, analysis of echocardiographic findings revealed larger EAT thickness at systole in the progression group $(4.2[3.2,5.4]$ vs. $3.8[2.9,4.8] \mathrm{mm}, P=0.014$; Additional file 2: Table S2). A logistic regression model including age, sex, BMI, hypertension, statin duration, prediabetes, and EAT thickness at systole showed that EAT thickness was an independent predictor of progression of impaired glucose tolerance (for each $1 \mathrm{~mm}$ of EAT thickness at systole: odds ratio of $1.309,95 \% \mathrm{CI}$ 1.117-1.534, $P=0.001$ ), and so was prediabetes (odds ratio of $3.265,95 \%$ CI 1.919-5.555, $P<0.001$; Additional file 2: Table S3). 
Table 1 Baseline characteristics of the total population

\begin{tabular}{|c|c|c|c|c|}
\hline & Total population & $\operatorname{NODM}(+)(n=40)$ & $\operatorname{NODM}(-)(n=281)$ & $P$ value \\
\hline \multicolumn{5}{|l|}{ Demographic findings } \\
\hline Age (years) & $60(51,69)$ & $60(51,72)$ & $59(51,69)$ & 0.950 \\
\hline Sex (male, \%) & $238(74.1 \%)$ & $30(75.0 \%)$ & $208(74.0 \%)$ & 0.895 \\
\hline BMI $\left(\mathrm{kg} / \mathrm{m}^{2}\right)$ & $24.9(23.2,27.1)$ & $25.8(23.7,28.0)$ & $24.8(23.2,27.0)$ & 0.184 \\
\hline $\mathrm{BMI}>25 \mathrm{~kg} / \mathrm{m}^{2}$ & $157(48.9 \%)$ & $23(57.5 \%)$ & $134(47.7 \%)$ & 0.245 \\
\hline Clinical diagnosis (\%) & & & & 0.984 \\
\hline Stable angina & $115(35.8 \%)$ & $14(35.0 \%)$ & 101 (35.9\%) & \\
\hline Unstable angina & $48(15.0 \%)$ & $7(17.5 \%)$ & $41(14.6 \%)$ & \\
\hline NSTEMI & $64(19.9 \%)$ & $7(17.5 \%)$ & $57(20.3 \%)$ & \\
\hline STEMI & $94(29.3 \%)$ & $12(30.0 \%)$ & $82(29.2 \%)$ & \\
\hline Hypertension (\%) & $127(39.6 \%)$ & $19(47.5 \%)$ & $108(38.4 \%)$ & 0.273 \\
\hline Current smoking (\%) & $84(26.2 \%)$ & $10(25.0 \%)$ & $74(26.3 \%)$ & 0.857 \\
\hline Previous CVA (\%) & $11(3.4 \%)$ & $0(0.0 \%)$ & $11(3.9 \%)$ & 0.203 \\
\hline Bronchial asthma (\%) & $5(1.6 \%)$ & $1(2.5 \%)$ & $4(1.4 \%)$ & 0.607 \\
\hline COPD (\%) & $9(2.8 \%)$ & $2(5.0 \%)$ & $7(2.5 \%)$ & 0.368 \\
\hline Dyslipidemia (\%) & $80(24.8 \%)$ & $9(22.5 \%)$ & $71(25.3 \%)$ & 0.705 \\
\hline Prediabetes (\%) & $130(40.5 \%)$ & $31(77.5 \%)$ & 99 (35.2\%) & $<0.001$ \\
\hline \multicolumn{5}{|l|}{ Laboratory findings } \\
\hline 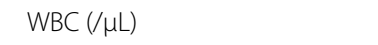 & $7900(5970,10,950)$ & $7640(5500,10,450)$ & $7900(6000,11,040)$ & 0.589 \\
\hline Hemoglobin (g/dL) & $14.6(13.5,15.6)$ & $15.0(13.6,15.8)$ & $14.5(13.4,15.6)$ & 0.246 \\
\hline Fasting blood glucose (mg/dL) & $92(84,103)$ & $98(90,107)$ & $92(84,102)$ & 0.010 \\
\hline $\mathrm{HbA1c}(\% / \mathrm{mmol} / \mathrm{mol})$ & $5.7(5.5,5.9) / 38.8(36.6,41.0)$ & $6.0(5.7,6.3) / 42.1(39.1,45.4)$ & $5.7(5.4,5.8) / 38.8(35.5,39.9)$ & $<0.001$ \\
\hline Total cholesterol (mg/dL) & $207(177,240)$ & $210(171,246)$ & $207(179,240)$ & 0.774 \\
\hline Triglyceride (mg/dL) & $133(90,209)$ & $145(99,214)$ & $131(89,209)$ & 0.414 \\
\hline HDL-cholesterol (mg/dL) & $42(37,50)$ & $40(35,47)$ & $43(37,51)$ & 0.100 \\
\hline LDL-cholesterol (mg/dL) & $133(110,157)$ & $126(112,157)$ & $133(108,157)$ & 0.979 \\
\hline Serum creatinine (mg/dL) & $0.88(0.73,1.01)$ & $0.84(0.76-1.00)$ & $0.98(0.73,1.02)$ & 0.524 \\
\hline hsCRP (mg/dL) & $0.15(0.10,0.31)$ & $0.15(0.10,0.25)$ & $0.15(0.10,0.32)$ & 0.264 \\
\hline \multicolumn{5}{|l|}{ Echocardiography } \\
\hline $\operatorname{LVEDD~(mm)~}$ & $48.0(44.3,51.9)$ & $49.0(45.0,52.1)$ & $48.0(44.0,51.9)$ & 0.408 \\
\hline $\operatorname{LVESD}(\mathrm{mm})$ & $31.0(27.0,35.0)$ & $32.0(29.0,34.6)$ & $30.3(26.9,35.1)$ & 0.319 \\
\hline LV ejection fraction (\%) & $60.0(53.5,64.7)$ & $60.3(54.9,66.1)$ & $59.5(53.1,64.5)$ & 0.246 \\
\hline Left atrium dimension (mm) & $37.1(33.7,41.0)$ & $36.8(34.1,40.0)$ & $37.4(33.7,41.0)$ & 0.624 \\
\hline EAT diastole (mm) & $1.4(1.0,2.2)$ & $2.2(1.4,3.5)$ & $1.2(1.0,2.1)$ & $<0.001$ \\
\hline EAT systole (mm) & $4.0(3.0,4.9)$ & $5.4(4.2,7.4)$ & $3.9(2.94 .8)$ & $<0.001$ \\
\hline \multicolumn{5}{|l|}{ Baseline medication } \\
\hline Aspirin & $321(100 \%)$ & $40(100 \%)$ & $281(100 \%)$ & NA \\
\hline Clopidogrel & $320(99.7 \%)$ & $40(100 \%)$ & $280(99.6 \%)$ & 0.706 \\
\hline ACE inhibitor or ARB & $275(85.7 \%)$ & 34 (85.0\%) & $241(85.8 \%)$ & 0.897 \\
\hline Beta blockers & $246(76.6 \%)$ & $30(75.0 \%)$ & 216 (76.9\%) & 0.794 \\
\hline Thiazides & $36(11.2 \%)$ & $4(10.0 \%)$ & $32(11.4 \%)$ & 0.795 \\
\hline Systemic steroid & $30(9.3 \%)$ & $3(7.5 \%)$ & $27(9.6 \%)$ & 0.668 \\
\hline Statin & & & & 0.128 \\
\hline Atorvastatin 40 mg & $204(63.6 \%)$ & $20(50.0 \%)$ & $184(65.5 \%)$ & \\
\hline Atorvastatin $80 \mathrm{mg}$ & $57(17.8 \%)$ & $11(27.5 \%)$ & $46(16.4 \%)$ & \\
\hline Rosuvastatin 20 mg & $60(18.7 \%)$ & $9(22.5 \%)$ & $51(18.1 \%)$ & \\
\hline
\end{tabular}


Table 1 continued

\begin{tabular}{|c|c|c|c|c|}
\hline & Total population & $\operatorname{NODM}(+)(n=40)$ & $\operatorname{NODM}(-)(n=281)$ & $P$ value \\
\hline \multicolumn{5}{|l|}{ Statin duration (days) } \\
\hline Total statin duration & $1248(984,1800)$ & $1348(983,1827)$ & $1237(984,1800)$ & 0.293 \\
\hline High intensity statin duration & $930(541,1216)$ & $963(785,1322)$ & $922(500,1210)$ & 0.297 \\
\hline
\end{tabular}

$A C E$ angiotensin-converting enzyme, $A R B$ angiotensin-receptor blocker, $B M I$ body mass index, COPD chronic obstructive pulmonary disease, $C V A$ cerebrovascular accident, EAT epicardial adipose tissue, $H D L$ high density lipoprotein, $h S C R P$ high-sensitivity C-reactive protein, ISR in-stent restenosis, $L D L$ low density lipoprotein, $L V$ left ventricular, LVEDD left ventricular end diastolic dimension, LVESD left ventricular end systolic dimension, MI myocardial infarction, NSTEMI non-ST-segment elevation myocardial infarction, STEMI ST-segment elevation myocardial infarction, WBC white blood cell

Table 2 Univaraite and multivariate analyses for new-onset diabetes mellitus

\begin{tabular}{|c|c|c|c|c|}
\hline \multirow[t]{2}{*}{ Factor } & \multicolumn{2}{|l|}{ Univariate analysis } & \multicolumn{2}{|l|}{ Multivariate analysis } \\
\hline & $\operatorname{HR}(95 \% \mathrm{Cl})^{*}$ & $P$ value & $\mathrm{HR}(95 \% \mathrm{Cl})^{*}$ & $P$ value \\
\hline Age & $0.999(0.975-1.023)$ & 0.909 & $0.978(0.950-1.007)$ & 0.130 \\
\hline Male sex & $1.029(0.502-2.108)$ & 0.938 & $1.220(0.539-2.765)$ & 0.633 \\
\hline $\mathrm{BMI}$ & $1.062(0.956-1.179)$ & 0.263 & $0.996(0.877-1.131)$ & 0.996 \\
\hline Diagnosis as acute coronary syndrome & $0.954(0.497-1.830)$ & 0.888 & - & - \\
\hline Hypertension & $1.524(0.818-2.838)$ & 0.184 & $1.727(0.872-3.420)$ & 0.117 \\
\hline Current smoking & $1.030(0.503-2.109)$ & 0.935 & - & - \\
\hline Dyslipidemia & $1.114(0.530-2.341)$ & 0.775 & - & - \\
\hline Prediabetes at baseline & $5.503(2.619-11.564)$ & $<0.001$ & $4.321(1.998-9.349)$ & $<0.001$ \\
\hline Anemia (Hemoglobin < 12 g/dL) & $2.745(0.377-19.985)$ & 0.319 & - & - \\
\hline TG level (per mg/dL) & $1.001(0.999-1.004)$ & 0.309 & - & - \\
\hline LDL-cholesterol level (per mg/dL) & $1.002(0.993-1.011)$ & 0.703 & - & - \\
\hline LV ejection fraction < 40\% & $2.153(0.296-15.672)$ & 0.449 & - & - \\
\hline EAT thickness at diastole (per mm) & $1.625(1.353-1.950)$ & $<0.001$ & & \\
\hline EAT thickness at systole (per mm) & $1.611(1.388-1.870)$ & $<0.001$ & $1.580(1.346-1.854)$ & $<0.001$ \\
\hline Total statin duration (per year) & $0.916(0.716-1.171)$ & 0.482 & $0.876(0.733-1.048)$ & 0.147 \\
\hline High intensity statin duration & $0.989(0.804-1.217)$ & 0.918 & - & - \\
\hline
\end{tabular}

$B M I$ body mass index, LV left ventricle, $L D L$ low density lipoprotein, $T G$ triglyceride, EAT epicardial adipose tissue

* The hazard ratio (HR) along with its corresponding $95 \%$ confidence interval (Cl) and p values are based on Cox proportional hazard analysis

\section{Discussion}

In this study involving patients who received PCI and were prescribed high-intensity statins for at least 6 months, NODM occurred in $12.5 \%$ of patients during a follow-up period of 3.9 years. Baseline EAT thickness at systole and prediabetes at baseline were revealed as two independent predictors for NODM. Patients with EAT thickness $\geq 5 \mathrm{~mm}$ and prediabetes at baseline had a 12.0-fold higher risk to develop NODM compared to the risk noted in patients without risk factors. Considering that echocardiography is performed in nearly all CAD patients undergoing $\mathrm{PCI}$, our study provides an easy-toobtain predictor of NODM in patients who require highdose statin treatment.

\section{Statins and risk of NODM in cardiovascular disease}

Statins are effective therapeutic agents for prevention of cardiovascular events, and can reduce mortality in patients with coronary heart disease [17]. However, recent studies reported that statin treatment may be associated with an increased risk of NODM. A metaanalysis of 13 trials involving 91,140 individuals showed that statin treatment was associated with a $9 \%$ increase in the 4-year risk of NODM [10]. Regarding the dose-effect relationship in statin-associated NODM, some studies have shown a higher risk of incident diabetes in patients on higher-intensity statin therapy $[9,18]$, while some suggest that there might be difference in the incident diabetes by statin class [19]. Large scale studies focusing on 


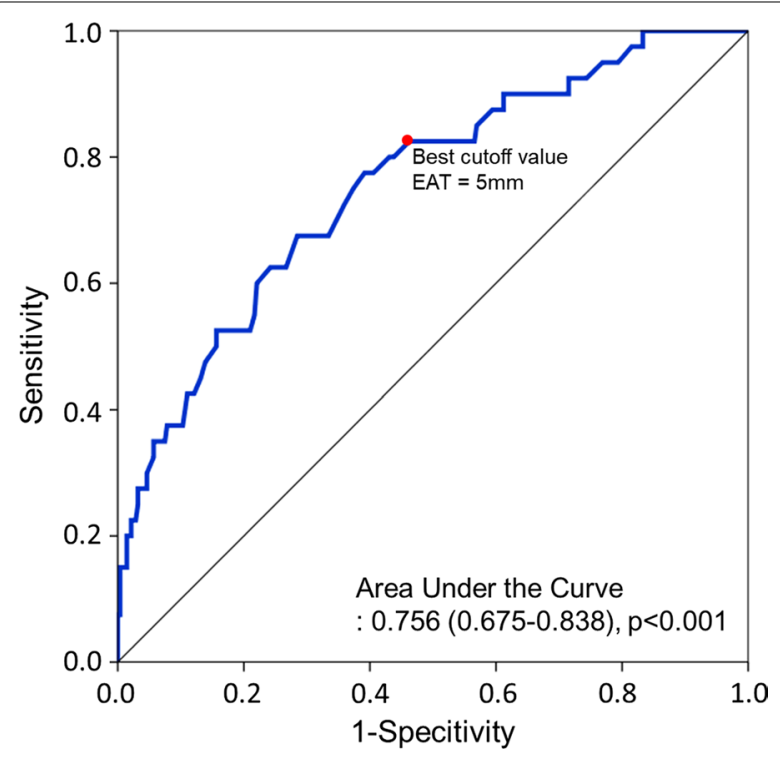

Fig. 1 The receiver operating characteristic curve for EAT thickness at systole and corresponding area under the curve (AUC) statistics for the risk of NODM

the occurrence of NODM by statin intensity or by statin class should be conducted to give us clear answers on this issue. Our present study found a similar rate of NODM in patients using high-intensity statins during 4 years of follow-up. Regarding previous reports showing that NODM is associated with a substantial risk for mortality [20], further efforts should be allocated to the early prediction and prevention of NODM [21].

\section{Biological relevance of the EAT}

The EAT is known as the true visceral fat deposit of the heart, lying directly on the epicardial surface of the myocardium within the pericardial sac [22]. Due to its close proximity to the coronary vessels, the EAT exerts profound effect on the local physiology of the myocardium and the coronary vasculature by expressing various cytokines [23]. Additionally, EAT was associated with cardiovascular risks and further development of cardiovascular complications [24]. EAT thickness has also been shown to be related to the metabolic status of the individual. Specifically, Yorgun et al. reported that EAT thickness was significantly increased in patients with metabolic syndrome, and that age and BMI, which are factors related to metabolic syndrome, were the strongest independent predictors of EAT thickness [25]. A recent meta-analysis also showed that EAT thickness was significantly higher in patients with metabolic syndrome [26]. Other studies have explained that the association between metabolic syndrome and EAT thickness may be attributed to the endocrine action of the EAT, which also affects insulin sensitivity [27], designating EAT as a biologically active organ. Conversely, some studies suggested the beneficial effect of EAT by protecting the heart against myocardial stress, hypertension, and local inflammation. EAT may even function as a brown adipose tissue store which can protect adjacent tissues from hypothermia, while showing high degrees of white adipose tissue lipolysis allowing the buffering of high toxic levels of free fatty acids [6]. Additionally, a genetic study explored the EAT transcriptome, unveiling a majority of genes involved in coagulation, endothelial function, phospholipase activity, apoptosis, and immune signaling [28]. Despite these beneficial effects, EAT may shift from being protective to detrimental for obesity and cardiovascular homeostasis [6]. Although the mechanisms that regulate the balance between protective and harmful effects of EAT are not clearly understood, epicardial fat can serve as target for pharmaceutical agents targeting the adipose tissue [29]. Furthermore, the association of EAT and diabetes has been studied in a few studies. Increased EAT thickness was independently associated with the prevalence of diabetes, insulin resistance and cardiac contractile dysfunction in diabetes [30,31]. In the present study, we found that EAT thickness was closely associated with NODM. Aside from prediabetes, which is a well-known risk factor for DM, EAT thickness was the only other significant predictor of statin-associated NODM.

\section{Clinical implications of EAT thickness as a predictor of statin-associated NODM}

Previous studies have reported conflicting results regarding the potential predictors of NODM. Specifically, the IDEAL study suggested that only patients who already have elevated risk for DM are at increased risk to develop statin-associated DM [32]. Furthermore, the Justification for Use of Statins in Prevention: an Intervention Trial Evaluating Rosuvastatin (JUPITER) study reported that the risk of statin-associated NODM was independent of baseline glucose levels, whereas Waters et al. reported that the development of NODM can be predicted based on baseline fasting glucose levels and other components of the metabolic syndrome (i.e., triglyceride levels, BMI, and hypertension) [33]. On the other hand, a cohortbased study by Woestijne et al. found that the increase in the risk of type $2 \mathrm{DM}$ with statin therapy was independent of metabolic syndrome or insulin resistance [13]. The discrepancies in these previous observations may be attributed to the differences in the study population, as well as to variable statin dosage and duration.

In the present study, we limited our study population to patients with CAD who underwent $\mathrm{PCI}$ and required strict lipid-lowering therapy and we were able to draw 


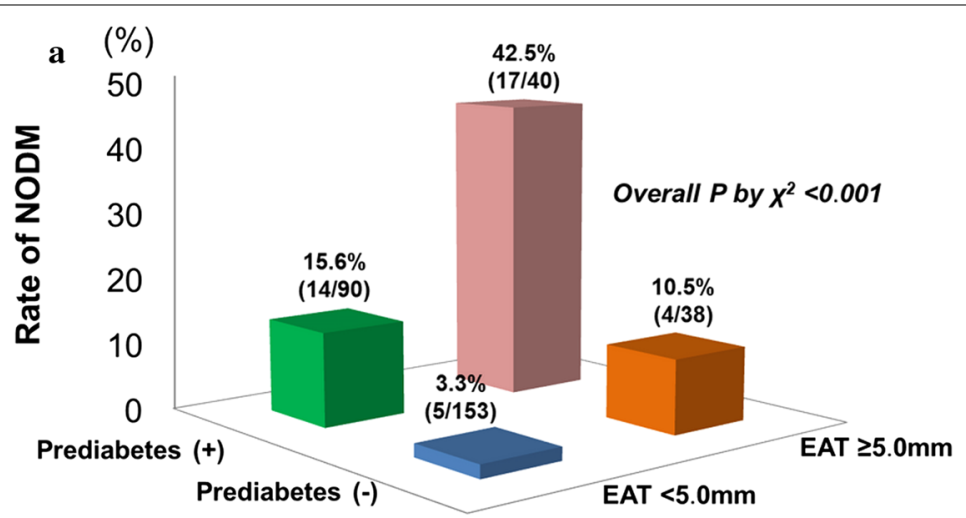

$\mathbf{b}$

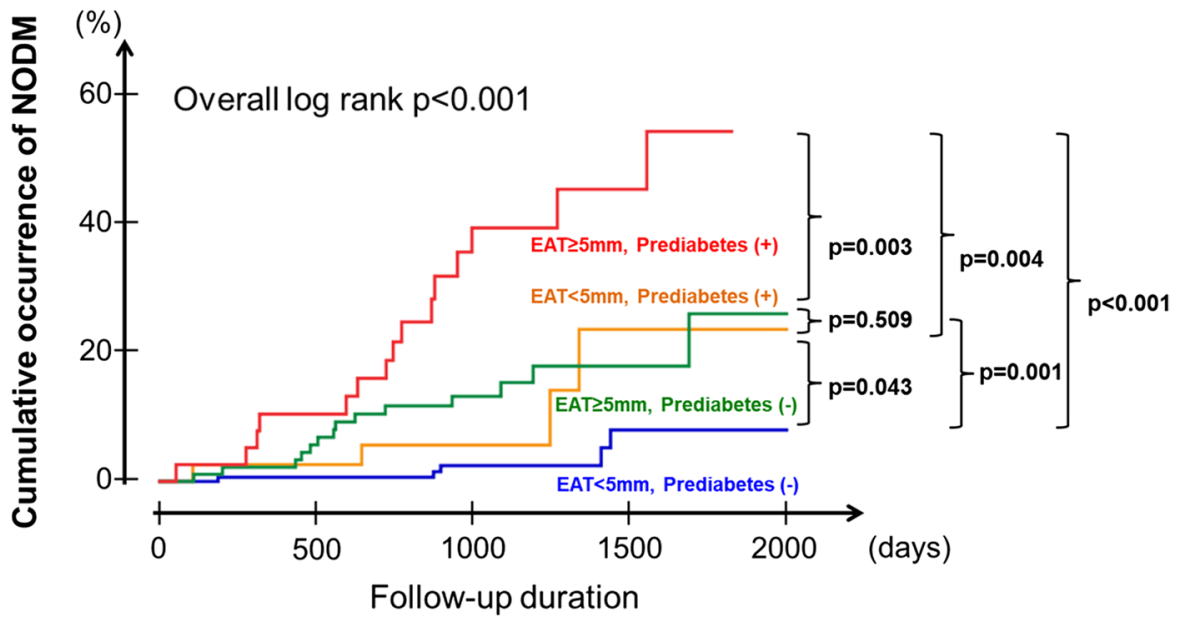

\begin{tabular}{lllll}
\hline No at risk & & & & \\
\hline EAT $<5 \mathrm{~mm}$, prediabetes $(-)$ & 153 & 140 & 78 & 31 \\
EAT $\geq 5 \mathrm{~mm}$, prediabetes $(-)$ & 38 & 33 & 17 & 4 \\
EAT $<5 \mathrm{~mm}$, prediabetes $(+)$ & 90 & 79 & 51 & 15 \\
EAT $\geq 5 \mathrm{~mm}$, prediabetes $(+)$ & 40 & 32 & 16 & 6
\end{tabular}

Fig. 2 Incidence of new-onset diabetes mellitus (NODM) according to epicardial adipose tissue (EAT) thickness at systole and the presence of prediabetes. a Among the total population, 153 patients had an EAT < $5 \mathrm{~mm}$ with no prediabetes at baseline (Group 1), 38 patients had an EAT $\geq 5 \mathrm{~mm}$ with no prediabetes at baseline (Group 2), 90 patients had an EAT $<5 \mathrm{~mm}$ with prediabetes at baseline (Group 3 ), and 40 patients had an EAT $\geq 5 \mathrm{~mm}$ with prediabetes at baseline (Group 4). Patients with EAT $\geq 5.0 \mathrm{~mm}$ and prediabetes at baseline had the highest incidence of NODM. Post-hoc analysis of NODM incidence showed that there were significant differences between all pairs of groups, except between Group 2 and Group 3 (Group 1 vs. Group 2,P=0.012; Group 1 vs. Group 3,P=0.001; Group 1 vs. Group 4,P<0.001; Group 2 vs. Group 3, $P=0.661$; Group 2 vs. Group 4, $P<0.001$; Group 3 vs. Group 4, $P<0.001$ ). b Kaplan-Meier survival curve showing an incremental increase in risk for NODM, according to the presence of prediabetes at baseline and EAT thickness

a conclusion based on a relatively homogeneous small sample of patients. Moreover, considering that echocardiography is performed in nearly all CAD patients receiving PCI, our finding that EAT thickness is a predictor of statin-associated NODM may have considerable clinical implication.

Despite the risk of statin-associated NODM, the general consensus is that the positive effects of statins outweigh the negative effects on metabolic control [34]. The
TNT study showed that patients at risk of statin-associated NODM also obtained substantial benefit from highintensity statins [11]. This finding may be related to the traditional effect of statins, which lower blood cholesterol levels, and have favorable pleiotropic effects on endothelial function, oxidative stress and inflammation [35]. Nevertheless, in clinical practice, it remains important to identify factors that can estimate the risk of statin-associated NODM. 
Table 3 Risk of new-onset diabetes mellitus according to the epicardial adipose tissue thickness and prediabetes

\begin{tabular}{llll}
\hline & HR & $\mathbf{9 5 \%} \mathrm{Cl}$ & P value \\
\hline $\begin{array}{l}\text { EAT thickness }<5 \mathrm{~mm} \text { and no } \\
\text { prediabetes }\end{array}$ & Reference & & \\
$\begin{array}{l}\text { EAT thickness } \geq 5 \mathrm{~mm} \text { and no } \\
\text { prediabetes }\end{array}$ & 3.481 & $0.934-12.972$ & 0.063 \\
$\begin{array}{l}\text { EAT thickness }<5 \mathrm{~mm} \text { and predia- } \\
\text { betes }\end{array}$ & 5.011 & $1.805-13.916$ & 0.002 \\
$\begin{array}{l}\text { EAT thickness } \geq 5 \mathrm{~mm} \text { and predia- } \\
\text { betes }\end{array}$ & 14.702 & $5.336-40.503<0.001$ \\
\hline
\end{tabular}

EAT epicardial adipose tissue, $H R$ hazard ratio, $C l$ confidence interval

\section{Limitations}

Several limitations should be noted. The study population was relatively small compared to cohorts investigated in previous studies or randomized controlled trials. Furthermore, we may have introduced selection bias by excluding patients prescribed with high-intensity statins for less than 6 months and those only prescribed with low- or moderate-intensity statin. Moreover, the patients in our study had various patterns of statin usage; specifically, some were not statin-naïve, and had been prescribed low- or moderate-intensity statins before receiving high-intensity statins. We also used a single method to measure EAT thickness. A previous study proposed a method to measure EAT thickness at the anterior interventricular groove, which may be more accurate than our method [36]. However, this measurement was not applicable in our retrospective analysis, because this echocardiographic view was not routinely used in our institute. Furthermore, our study did not include a control arm, which made it impossible to investigate the association between high-dose statin and NODM. However, this was not the purpose of our study, but rather its background. Therefore, the findings of our investigation may be considered as hypothesis-generating, and further large-scale studies are warranted.

\section{Additional files}

Additional file 1: Figure S1. Selection of Study population. Figure

S2. Method of EAT thickness measurement. Representative figure of EAT measurement. EAT thickness was measured at the end of systole and diastole at the free wall of the right ventricle, in the parasternal long axis view. Figure S3. Bland-Altman plot for Intra-observer variability. A Bland-Altman plot proved excellent agreement between the two measurements of EAT thickness at systole within one observer. Figure S4. A scatter plot of EAT thickness and the occurrence of new-onset diabetes mellitus. Figure S5. Linear correlation between $\mathrm{HbA1c}$ and EAT thickness.

Additional file 2: Table S1. Changes in glucose tolerance status. Table S2. Baseline clinical characteristics of the total population, grouped by progression of glucose intolerance. Table S3. Multivariate analysis for progression in impairment of glucose tolerance.

\section{Abbreviations}

DM: diabetes mellitus; NODM: new-onset diabetes mellitus; EAT: epicardial adipose tissue; CAD: coronary artery disease; PCl: percutaneous coronary intervention; HR: hazard ratio; $\mathrm{Cl}$ : confidential interval.

\section{Authors' contributions}

JK performed analysis/interpretation of data and drafting of manuscript, YCK and SK performed echocardiographic data analysis, JJP, SHK contributed in analysis of data, YJC, YEY, IYO, CHY, JWS contributed in acquisition of patients and data, YSC provided the study conception and drafting of manuscript, TJY, IHC, DJC provided consultation on the study concept and critical revision. All authors read and approved the final manuscript.

\section{Author details}

1 Department of Internal Medicine, Seoul National University Bundang Hospital, 82 Gumiro173 Beongil, Bundang, Seongnam, Gyeonggi 13620, South Korea. ${ }^{2}$ Department of Internal Medicine, Seoul National University Hospital, Seoul, South Korea. ${ }^{3}$ Division of Cardiology, Hallym University Hangang Sacred Heart Hospital, Seoul, South Korea. ${ }^{4}$ Seoul National University College of Medicine, Seoul, South Korea.

\section{Acknowledgements}

None.

\section{Competing interests}

The authors declare that they have no competing interests.

\section{Availability of data and materials}

The datasets generated and/or analysed during the current study are not publicly available due regulations of patient information to be released in public, but are available from the corresponding author on reasonable request, after anonymization.

\section{Consent for publication}

All patients provided informed consent for undergoing the investigations, and for publication.

\section{Ethics approval and consent to participate}

The study protocol was approved by the Institutional Review Board of Seoul National University Bundang Hospital and was conducted according to the principles of the Declaration of Helsinki.

\section{Funding}

None.

\section{Publisher's Note}

Springer Nature remains neutral with regard to jurisdictional claims in published maps and institutional affiliations.

Received: 8 September 2017 Accepted: 23 December 2017

Published online: 11 January 2018

\section{References}

1. lacobellis G, Assael F, Ribaudo MC, Zappaterreno A, Alessi G, Di Mario U, Leonetti F. Epicardial fat from echocardiography: a new method for visceral adipose tissue prediction. Obes Res. 2003;1 1(2):304-10.

2. lacobellis G, Ribaudo MC, Assael F, Vecci E, Tiberti C, Zappaterreno A, Di Mario U, Leonetti F. Echocardiographic epicardial adipose tissue is related to anthropometric and clinical parameters of metabolic syndrome: a new indicator of cardiovascular risk. J Clin Endocrinol Metab. 2003:88(11):5163-8.

3. Jeong JW, Jeong MH, Yun KH, Oh SK, Park EM, Kim YK, Rhee SJ, Lee EM, Lee J, Yoo NJ, et al. Echocardiographic epicardial fat thickness and coronary artery disease. Circ J. 2007;71(4):536-9.

4. lacobellis G, Barbaro G, Gerstein HC. Relationship of epicardial fat thickness and fasting glucose. Int J Cardiol. 2008:128(3):424-6.

5. Sironi AM, Pingitore A, Ghione S, De Marchi D, Scattini B, Positano V, Muscelli E, Ciociaro D, Lombardi M, Ferrannini E, et al. Early hypertension 
is associated with reduced regional cardiac function, insulin resistance, epicardial, and visceral fat. Hypertension. 2008;51 (2):282-8.

6. Gonzalez N, Moreno-Villegas Z, Gonzalez-Bris A, Egido J, Lorenzo O. Regulation of visceral and epicardial adipose tissue for preventing cardiovascular injuries associated to obesity and diabetes. Cardiovasc Diabetol. 2017;16(1):44

7. lacobellis G, Willens HJ, Barbaro G, Sharma AM. Threshold values of highrisk echocardiographic epicardial fat thickness. Obesity (Silver Spring). 2008;16(4):887-92.

8. Stone NJ, Robinson JG, Lichtenstein AH, Bairey Merz CN, Blum CB, Eckel RH, Goldberg AC, Gordon D, Levy D, Lloyd-Jones DM, et al. 2013 ACC/ AHA guideline on the treatment of blood cholesterol to reduce atherosclerotic cardiovascular risk in adults: a report of the American College of Cardiology/American Heart Association Task Force on Practice Guidelines. Circulation. 2014;129(25 Suppl 2):S1-45.

9. Dormuth CR, Filion KB, Paterson JM, James MT, Teare GF, Raymond CB, Rahme E, Tamim H, Lipscombe L. Canadian Network for Observational Drug Effect Studies I: higher potency statins and the risk of new diabetes: multicentre, observational study of administrative databases. BMJ. 2014;348:93244.

10. Sattar N, Preiss D, Murray HM, Welsh P, Buckley BM, de Craen AJ, Seshasai SR, McMurray JJ, Freeman DJ, Jukema JW, et al. Statins and risk of incident diabetes: a collaborative meta-analysis of randomised statin trials. Lancet. 2010;375(9716):735-42.

11. Deedwania P, Barter P, Carmena R, Fruchart JC, Grundy SM, Haffner S, Kastelein JJ, LaRosa JC, Schachner H, Shepherd J, et al. Reduction of lowdensity lipoprotein cholesterol in patients with coronary heart disease and metabolic syndrome: analysis of the treating to new targets study. Lancet. 2006;368(9539):919-28.

12. Faergeman O, Holme I, Fayyad R, Bhatia S, Grundy SM, Kastelein JJ, LaRosa JC, Larsen ML, Lindahl C, Olsson AG, et al. Plasma triglycerides and cardiovascular events in the treating to new targets and incremental decrease in end-points through aggressive lipid lowering trials of statins in patients with coronary artery disease. Am J Cardiol. 2009;104(4):459-63.

13. van de Woestijne AP, van der Graaf Y, Westerink J, Nathoe HM, Visseren FL. Effect of statin therapy on incident type 2 diabetes mellitus in patients with clinically manifest vascular disease. Am J Cardiol. 2015;1 15(4):441-6.

14. American Diabetes A. 2. Classification and diagnosis of diabetes. Diabetes Care. 2017:40(Suppl 1):S11-24.

15. Kim MJ, Lim NK, Choi SJ, Park HY. Hypertension is an independent risk factor for type 2 diabetes: the Korean genome and epidemiology study. Hypertens Res. 2015;38(11):783-9.

16. Chang SA. Smoking and type 2 diabetes mellitus. Diabetes Metab J. 2012:36(6):399-403.

17. Allen Maycock CA, Muhlestein JB, Horne BD, Carlquist JF, Bair TL, Pearson RR, Li Q, Anderson JL, Intermountain Heart Collaborative S. Statin therapy is associated with reduced mortality across all age groups of individuals with significant coronary disease, including very elderly patients. J Am Coll Cardiol. 2002;40(10):1777-85.

18. Preiss D, Seshasai SR, Welsh P, Murphy SA, Ho JE, Waters DD, DeMicco DA, Barter P, Cannon CP, Sabatine MS, et al. Risk of incident diabetes with intensive-dose compared with moderate-dose statin therapy: a metaanalysis. JAMA. 2011;305(24):2556-64.

19. Vallejo-Vaz AJ, Kondapally Seshasai SR, Kurogi K, Michishita I, Nozue T, Sugiyama S, Tsimikas S, Yoshida H, Ray KK. Effect of pitavastatin on glucose, $\mathrm{HbA1} \mathrm{C}$ and incident diabetes: a meta-analysis of randomized controlled clinical trials in individuals without diabetes. Atherosclerosis. 2015;241(2):409-18

20. Barnett KN, Ogston SA, McMurdo ME, Morris AD, Evans JM. A 12-year follow-up study of all-cause and cardiovascular mortality among 10,532 people newly diagnosed with Type 2 diabetes in Tayside, Scotland. Diabet Med. 2010;27(10):1124-9.

21. Zucker I, Shohat T, Dankner R, Chodick G. New onset diabetes in adulthood is associated with a substantial risk for mortality at all ages: a population based historical cohort study with a decade-long follow-up. Cardiovasc Diabetol. 2017:16(1):105.
22. lacobellis G, Willens HJ. Echocardiographic epicardial fat: a review of research and clinical applications. J Am Soc Echocardiogr. 2009;22(12):1311-9 (quiz 1417-1318).

23. Christensen RH, von Scholten BJ, Hansen CS, Heywood SE, Rosenmeier $\mathrm{JB}$, Andersen UB, Hovind P, Reinhard H, Parving HH, Pedersen BK, et al. Epicardial, pericardial and total cardiac fat and cardiovascular disease in type 2 diabetic patients with elevated urinary albumin excretion rate. Eur J Prev Cardiol. 2017;24(14):1517-24.

24. Wang Z, Zhang Y, Liu W, Su B. Evaluation of epicardial adipose tissue in patients of type 2 diabetes mellitus by echocardiography and its correlation with intimal medial thickness of carotid artery. Exp Clin Endocrinol Diabetes. 2017;125(9):598-602.

25. Yorgun H, Canpolat U, Hazirolan T, Ates AH, Sunman H, Dural M, Sahiner L, Kaya EB, Aytemir K, Tokgozoglu L, et al. Increased epicardial fat tissue is a marker of metabolic syndrome in adult patients. Int J Cardiol. 2013;165(2):308-13.

26. Pierdomenico SD, Pierdomenico AM, Cuccurullo F, lacobellis G. Metaanalysis of the relation of echocardiographic epicardial adipose tissue thickness and the metabolic syndrome. Am J Cardiol. 2013;111(1):73-8.

27. lacobellis $\mathrm{G}$, Leonetti F. Epicardial adipose tissue and insulin resistance in obese subjects. J Clin Endocrinol Metab. 2005;90(11):6300-2.

28. McAninch EA, Fonseca TL, Poggioli R, Panos AL, Salerno TA, Deng Y, Li Y, Bianco AC, lacobellis G. Epicardial adipose tissue has a unique transcriptome modified in severe coronary artery disease. Obesity (Silver Spring). 2015;23(6):1267-78.

29. lacobellis G. Epicardial fat: a new cardiovascular therapeutic target. Curr Opin Pharmacol. 2016;27:13-8.

30. Levelt E, Pavlides M, Banerjee R, Mahmod M, Kelly C, Sellwood J, Ariga R, Thomas S, Francis J, Rodgers C, et al. Ectopic and visceral fat deposition in lean and obese patients with type 2 diabetes. J Am Coll Cardiol. 2016;68(1):53-63.

31. Chun H, Suh E, Byun AR, Park HR, Shim KW. Epicardial fat thickness is associated to type 2 diabetes mellitus in Korean men: a cross-sectional study. Cardiovasc Diabetol. 2015;14:46.

32. Pedersen TR, Faergeman O, Kastelein JJ, Olsson AG, Tikkanen MJ, Holme I, Larsen ML, Bendiksen FS, Lindahl C, Szarek M, et al. High-dose atorvastatin vs usual-dose simvastatin for secondary prevention after myocardial infarction: the IDEAL study: a randomized controlled trial. JAMA. 2005;294(19):2437-45.

33. Waters DD, Ho JE, DeMicco DA, Breazna A, Arsenault BJ, Wun CC, Kastelein $\mathrm{JJ}$, Colhoun H, Barter P. Predictors of new-onset diabetes in patients treated with atorvastatin: results from 3 large randomized clinical trials. J Am Coll Cardiol. 2011;57(14):1535-45.

34. Shah RV, Goldfine AB. Statins and risk of new-onset diabetes mellitus. Circulation. 2012;126(18):e282-4.

35. Zhou Q, Liao JK. Pleiotropic effects of statins. Basic research and clinical perspectives. Circ J. 2010;74(5):818-26.

36. Hirata Y, Yamada H, Kusunose K, Iwase T, Nishio S, Hayashi S, Bando M, Amano R, Yamaguchi K, Soeki T, et al. Clinical utility of measuring epicardial adipose tissue thickness with echocardiography using a highfrequency linear probe in patients with coronary artery disease. J Am Soc Echocardiogr. 2015;28(10):1240-6

\section{Submit your next manuscript to BioMed Central and we will help you at every step:}

- We accept pre-submission inquiries

- Our selector tool helps you to find the most relevant journal

- We provide round the clock customer support

- Convenient online submission

- Thorough peer review

- Inclusion in PubMed and all major indexing services

- Maximum visibility for your research

Submit your manuscript at www.biomedcentral.com/submit 